\title{
Long-Term Morbidity of Infantile Eczema
}

\author{
Arnaldo Cantani* \\ Pediatric Clinic, University "La Sapienza" Roma, Italy
}

Submission: January 18, 2017; Published: January 31, 2017

*Corresponding author: Arnaldo Cantani, Pediatric Clinic, University “La Sapienza” Roma, Italy

\begin{abstract}
Human mankind is aware of the existence of adverse reactions to foods since classical times. Hippocrates (460-370 BC) reported urticaria and gastrointestinal upset following cow's milk (CM) ingestion. Lucretius (98-55 BC) wrote "Quod aliis cibus est aliis fuat acre venenum". Galen (131- 219) described allergy to goat's milk. At the turn of this century the first description of acute shock due to CM allergy was published, and Schloss was the first to evaluate skin tests for the diagnosis [1].
\end{abstract}

Abbreviations: CM: Cow's Milk; AD: Atopic Dermatitis; FH: Food Hypersensitivity

\section{Introduction}

Accordingly the aspiration to influence the natural incidence of atopic illness has piqued physicians' imaginations for a long time. The phenotypic expression of IgE-mediated disorders, which appears regulated by multiple genetic factors and modulated by environmental experiences, has been a target for prevention medicine since the 1920s when dietary intervention was adopted in infancy. During the past 70 years, controversy has emerged from clinical studies designed to evaluate the effect of dietary and environmental exclusions on the subsequent manifestations of atopy. Since then, a vastarray of articles has been published, which were only matched by endless discussions on the terms to be used. The lack of a single, practical diagnostic test has contributed to the polarization of the scientific controversy between «believers» and «nonbelievers». The problem posed by few diseases like atopic dermatitis (AD) is compounded by the difficulties experienced in its treatment. AD cannot benefit from pre-arranged therapeutic protocols, and is cause of invaluable and long-term physical and emotional suffering for children and parents. Therefore AD confronts doctors with one of the most demanding challenges [2].

\section{Case Report}

In a 5 -yr prospective study on 56 children (32 M, $24 \mathrm{~F}$ ) affected with food hypersensitivity (FH) fulfill $\neg$ ing the criteria for the AD diagnosis [3]. A 4-wk diagnostic elimi $\neg$ na $\neg$ tion diet was prescribed for diagnostic purposes. CM and dairy prod $\neg$ ucts were avoided if $\mathrm{AD}$ appeared when milk was the only feeding. If $\mathrm{AD}$ occurred when egg and wheat were also given, these foods were avoided. Further foods were eliminated following anamnestic data. Soy-milk (Isomil, Abbott), lamb-meat baseddiet1, and other nutritionally adequate food equivalents were employed. An open challenge test was done when skin lesions cleared-up. If no immediate reaction ensued, food was fed in a normal way, and the skin accurately checked by parents. At each visit the severity of skin lesions was evaluated. On the basis of the challenge test, a therapeutic elimination diet, excluding the offending foods, was given independently of IgE and/or skin test response. All patients were checked every year or more frequently if necessary.

The following parameters were studied at the 5-yr follow-up: age; AD severity score; development of food tolerance; duration of symptoms; respiratory allergy (asthma and/or rhinitis). Total IgE determination was not performed by 7 children, and skin tests and/or IgE to food/inhalant allergens by 13. Due to previous severe ana-phylactic reactions the challenge test to egg was not done in 7 patients and to CM in [3]. The median age (MA) of the children at the first examination was $3 \mathrm{yr}$. MA at $\mathrm{AD}$ onset was 3 months, before the 4 th month of life in 27 babies (48\%); between the 4 th and 6 th mo in 10 babies (18\%), and after the 6th mo in 19 babies (34\%). Mean severity score of AD was 17. Family history of atopy was positive in 23 patients (41\%). Skin le $\neg$ sions were typical in 43 children $(77 \%)$ and widespread or not typical (reverse pattern) in 13 (23\%); 19 patients (34\%) had respiratory allergy.

CM formulas were given since birth in 23 (41\%), before the 3rd mo in 18 (32\%), after the 3rd mo in 15 cases (27\%). Total 
IgE levels were higher than 2 SD for age in $39 / 49$ children (80\%). Skin tests and/or IgE to food allergens were positive in $45 / 55$ children (82\%), and to inhalant allergens in $26 / 44$ children (59\%). Main offending foods were CM and egg in 40\%, CM alone and egg in $14 \%$, and wheat in $2 \%$ of children. Polysensitivity was present mainly towards CM, egg and wheat in $29 \%$ of patients. $10 / 56$ children (18\%) were sensitive to wheat. At the followup the children's MA was $6 \mathrm{yr}+9$ mo. Skin lesions cleared up in $32(57 \%)$ children, persisted in $24(43 \%) .60 \%$ of children completely lost $\mathrm{FH}, 14 \%$ achieved a partial tolerance, in $26 \% \mathrm{FH}$ persisted. There was no differ 7 ence in the MA of these 3 groups. The MA for tolerance to $\mathrm{CM}$ was $3 \mathrm{yr}+6 \mathrm{mo}$, to egg $4 \mathrm{yr}$, and to wheat $4 \mathrm{yr}+6 \mathrm{mo}$.

There was no age difference at the first examination and at the follow-up in the groups with and without tolerance. There was a significant difference $(\mathrm{p}=0.0001)$ in the age of AD onset in the group with tolerance (MA 3 mo) and in the group without tolerance. 28 children (50\%) had respiratory allergy at the follow-up, 21 patients (37\%) developed asthma, 2 (4\%) rhinitis, and $5(9 \%)$ asthma and rhinitis. The children were divided into two groups: 24 with persisting AD, and 32 with cleared-up AD. There was a signif $\neg$ icant relationship between AD outcome and the age of onset of the skin lesions. In 25/32 children (78\%) with cleared-up AD the onset was before and in $12 / 24$ children (50\%) with persisting AD after the 6th mo of life ( $\mathrm{p}=0.023)$. There was a significant relationship between AD outcome and the skin lesion distribution at the first examination. 29/32 children with healing (91\%) had typical skin lesions at the first ex $\neg$ amination, while in $10 / 24$ children (42\%) with persisting $\mathrm{AD}$ the lesions were not typical or widespread $(\mathrm{p}=0.0001)$. A significant relationship was found between AD out-come and the de רvelopment of food tolerance. $95 \%$ of children with healing achieved a complete or partial tolerance to the offending foods, while $50 \%$ with persisting AD failed to lose $\mathrm{FH}(\mathrm{p}=0.0007)$.
Additional significant differences between the two groups were found regarding association with respiratory allergy $(\mathrm{p}=0.0007)$, total $(\mathrm{p}=0.0001)$ and specific $\operatorname{IgE}(\mathrm{p}=0.0001)$, the relationship between development of tolerance and symptoms $(p=0.0026)$ and between tolerance and development of additional allergies $(\mathrm{p}=0.035)$, while no difference was found for family history of atopy, sex, AD severity score, and skin test responses. At the last follow-up the children were divided into those with and without respiratory al $\neg$ lergy. Both groups had a similar MA (6 yr+2/3 mo). There was a significant relationship between the respiratory allergy prevalence at the last follow-up and the positivity of skin tests and/or IgE to inhalant aller 7 gens at the first examination. $11 / 18$ children without respiratory allergy (39\%) had positive skin tests and/or IgE to inhalant allergens, while 19/26 children (73\%) with respiratory allergy at the last follow-up had positive skin tests and/or IgE to inhalant allergens at the first examination $(\mathrm{p}=0.023)$.

\section{Conclusion}

Several parameters were significantly $(0.023=\mathrm{p}=0.0001)$ associated with persisting skin lesions [2]. This confirms that few diseases like AD, although not being lethal, are causes of invalu $a$ able physical and emotional suffering either for children or their parents [4].

\section{Reference}

1. Cantani A, Ferrara M (1989) Allergische Krankheiten der Kinder: Diagnostik und Therapie. Eur Rev Med Pharmacol Sci 11: 483-488.

2. Businco L, Ziruolo MG, Ferrara M, Benincori N, Muraro A, et al. (1989) Natural history of atopic dermatitis in childhood. Allergy 44(9): 70-78.

3. Hanifin JM, Lobitz WC (1977) Newer concepts of atopic dermatitis. Arch Dermatol 113(5): 663-670.

4. Cantani A (1991) Management of infants with cow's milk allergy. Riv Eur Sci Med Farmacol 13(5-6): 195-198.

\author{
Your next submission with Juniper Publishers \\ will reach you the below assets \\ - Quality Editorial service \\ - Swift Peer Review \\ - Reprints availability \\ - E-prints Service \\ - Manuscript Podcast for convenient understanding \\ - Global attainment for your research \\ - Manuscript accessibility in different formats \\ ( Pdf, E-pub, Full Text, Audio) \\ - Unceasing customer service
}

Track the below URL for one-step submission https://juniperpublishers.com/online-submission.php 